\title{
Translating Interviews, Translating Lives: Ethical Considerations in Cross-Language Narrative Inquiry
}

Through two narrative inquiries, in this article I explore the challenges for qualitative researchers in working with multiple languages in capturing, translating, analyzing, and representing narratives. I discuss the effect on research when we engage in these processes considering what was happening as we translated both texts and experience from one language into another. Woven into this discussion is attention to the effect that choosing one language or another might have on our research: the participants, the processes, and the findings. I consider how to remain awake to the ethical and relational issues regarding language choices that we make at every step of the research process.

Par le biais de deux enquêtes narratives, je me penche sur les défis qu'affrontent ceux qui font de la recherche qualitative impliquant plusieurs langues à capturer, traduire, analyser et représenter les récits. Je discute de l'impact de ces processus sur la recherche en tenant compte de ce qui se passait quand nous traduisions tant des textes que des expériences d'une langue à l'autre. L'effet que pourrait avoir le fait de choisir une langue plutôt qu'une autre sur la recherche, les participants, les procédures et les résultats sert de trame à la discussion. Je prends en compte les façons de demeurer vigilant face aux enjeux sur le plan éthique et relationnel qui découlent des choix langagiers qu'on fait à chaque étape d'une recherche.

\section{Introduction}

Born and raised in Shanghai, China, I moved to Edmonton as a landed immigrant in September 1998 and started graduate school in the Faculty of Education, University of Alberta. Previously I had taught English for almost 10 years in Tong Ji University and worked as an interpreter and translator at a Shanghai TV Station for two years. I obtained my Master of Education degree in June 2001 and my doctorate in June 2006. My master's work was a narrative inquiry (Clandinin \& Connelly, 2000) into the transitional experiences of four Chinese international students as they moved from a Chinese high school to a Canadian high school and later to a Canadian university ( $\mathrm{Li}$, 2001). My doctoral dissertation, also a narrative inquiry, explored three Chinese international students' experiences of home and homelessness in Canada (Li, 2006). 
In this article I explore the challenges that I experienced working with both the Chinese and English languages while undertaking these two narrative inquiries into the experiences of Chinese international students in Canada. Before I make these challenges visible as I inquire into four moments that I experienced, I describe the methodology of narrative inquiry and then discuss ethics in narrative inquiry.

\section{Narrative Inquiry}

Connelly and Clandinin (2006) wrote:

arguments for the development and use of narrative inquiry come out of a view of human experience in which humans, individually and socially, lead storied lives. People shape their daily lives by stories of who they and others are and as they interpret their past in terms of these stories. Story is a portal through which a person enters the world and by which their experience of the world is interpreted and made personally meaningful. Narrative inquiry, the study of experience as story, is first and foremost a way of thinking about experience. (p. 477)

Central to understanding narrative inquiry is a three-dimensional inquiry space with its dimensions of temporality, sociality, and place (Clandinin \& Connelly, 2006).

The temporality dimension draws attention to the past, present, and future of events and people under study. Instead of just describing things or people as they are, narrative inquirers "give a temporal picture of each in transition" (Clandinin \& Connelly, 2006, p. 480). The sociality dimension points to both personal and social conditions. Narrative inquirers attend to "the feelings, hopes, desires, aesthetic reactions, and moral dispositions of the person, whether inquirer or participant" as well as "the existential conditions, the environment, surrounding factors and forces, people and otherwise, that form the individual's context" (p. 480). Another aspect of the sociality dimension draws attention to the relationship between participants and inquirers. Instead of bracketing out, "narrative inquirers bracket themselves into an inquiry" (p. 480) as we are "always in an inquiry relationship with participants' lives. We cannot subtract ourselves from relationship" (p. 480). The place dimension draws attention to "the specific concrete, physical and topological boundaries of place where the inquiry and events take place" (pp. 480-481). Thinking through the qualities of place and the effect of these specific places on the study is crucial for narrative inquirers. Attending to all three dimensions simultaneously is important in a narrative inquiry.

Working within this three-dimensional narrative inquiry space, I begin with the "telling" (Connelly \& Clandinin, 2006) of a moment that troubled 
me at the beginning of my doctoral work and then move backward in time to my experiences as a novice narrative inquirer unaware of the ethical issues involved in working with two languages for my master's thesis. I then move forward to describe what I did differently for my doctoral dissertation after I was awakened to the ethical tensions of translating stories and lives between the English and Chinese languages. I also discuss my thoughts and feelings as I learned to become a narrative inquirer in the Department of Secondary Education, University of Alberta. I conclude by "retelling" (Connelly \& Clandinin) these experiences, that is, to inquire into and interpret them in order to "offer possibilities for reliving, for new directions and new ways of doing things" (Connelly \& Clandinin, 2000, p. 189) as a narrative inquirer, becoming more conscious of the language choices I make in my future narrative inquiries.

\section{Ethics in Narrative Inquiry}

Drawing on their earlier work of studying teachers' knowledge of classrooms in schools, Clandinin and Connelly (1988) argued for a central place of relationships in collaborative narrative inquiry. "Relationship is key to what it is that narrative inquirers do" (Clandinin \& Connelly, 2000, p. 189). When they first began to reflect on an ethical incident involving a teacher participant, Ellen, and a research project assistant, Charles, that ended unhappily (Clandinin \& Connelly, 1988) more than two decades ago, they were challenged to reconsider the concept of negotiation, the ethics of participation, and the concept of practitioner/academic collaborative research. Although they had formulated a set of seven ethical principles and working procedures to ensure that these concerns would be addressed, the principles, however, did not "guarantee a fruitful study" (p. 281). They became aware that "something more was at work as their and others' lives as researchers became entangled in inquiry with the lives of participants" (Huber, Clandinin, \& Huber, 2006, p. 211). They came to realize what lived at the heart of a narrative inquiry: the ongoing negotiation of relationships between researchers and participants as their lives met in the inquiry. This "negotiation of two people's narrative unities" (Clandinin \& Connelly, 1988, p. 281), that is, the generating and sharing of a new shared narrative for both researcher and participant, required "a close relationship akin to friendship" (p. 281).

As Clandinin and Connelly (2000) continued to think about the nature of collaborative narrative inquiry and its relational aspects, they advocated considering ethical matters from a relational point of view. By reframing ethical concerns into concerns of relational responsibility (Clandinin \& Connelly; Craig \& Huber, 2007; Huber \& Clandinin, 2002; Huber et al., 2006; Lieblich, 1996; Schulz, 1997), they offered narrative inquirers another way to think through the many layers of complexities, uncertainties, and possibilities that are inherent in the unfolding of a narrative inquiry as we live in the field 
alongside participants, compose field texts, and later write interim and research texts. For Clandinin and Connelly,

ethical matters need to be narrated over the entire narrative inquiry process. They are not dealt with once and for all, as might seem to happen, when ethical review forms are filled out and university approval is sought for our inquiries. Ethical matters shift and change as we move through an inquiry. They are never far from the heart of our inquiries no matter where we are in the inquiry process. (p. 170)

So it was the case for my work with the Chinese international students. While I completed the ethics forms required by the University of Alberta's ethics board, I knew that I needed to continue to think about how to work with each participant in my studies in relational ethical ways throughout the inquiry process. However, looking back, I do not think that I was always aware of the ethical issues inherent in working with two languages and translating stories and lives from one to the other and how this might have affected my research participants' lives as well as the research process until the moment when I was awakened.

\title{
Challenges of Working with Two Languages in Narrative Inquiry
}

Storied Moment 1: Waking Up

\author{
My Heart Broke \\ My heart broke \\ on a rainy spring/snowy winter day \\ when I left behind
}

my one and a half year old daughter

two jobs

and a comfortable home

My heart broke

when I learned

my two-year-old daughter

was going to a universal daycare

where she would spend

five days and four nights a week

on her own 


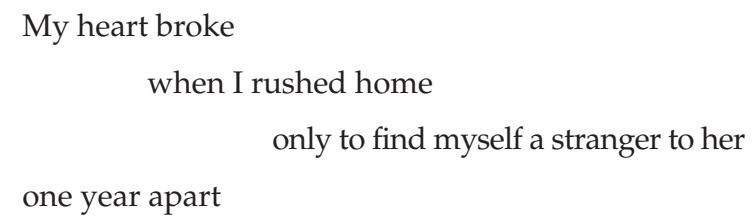

in two different new worlds

we both struggled, alone ...

My heart broke

when I had to leave her behind

the second time

in the hope

I would finish my degree

S-O-O-n

My heart broke

when that dream floating away

I collapsed

running away from campus

into the mountains

to die alone

My heart broke

when my daughter followed me

wherever I went

Canada, a strange new place

she was afraid

I would disappear the third time

and leave her alone

My heart broke

when I realized

what a fragmented life

I had lived

in those three years

on a foreign land

not my own 
As shown in my poem, my experiences as a new immigrant, a mother, a wife, and a graduate student during my first three years in Canada were full of struggle. Because of job and graduate study opportunities, I was separated from my loved ones. At that time, I lived in Edmonton. My husband worked in Jasper, and our baby daughter stayed with my parents-in-law in Shanghai.

As I wrote this poem on November 2, 2001, I was working on a pilot project for my doctoral dissertation. The title came to me a few days before the actual writing. When I sat in front of the computer, thinking about my leaving-home and going-home experiences, this poem in English seemed to pour right out of my fingertips. I remember my surprise that the poem came to me in English, my second language. I had another surprise when I tried to translate it into Chinese as I found it awkward to express strong emotions in my first language. In Chinese, my poem sounded remote and detached from my reality. How could this happen? I asked myself. Then a new and uncomfortable question emerged: If I could not translate my experiences in English in Canada into my Chinese language, what was happening to the research participants Jasmine, Magnolia, Mei, and Rose (all pseudonyms chosen by participants) when I translated their experiences from Chinese into English as I wrote my thesis? This poem-writing experience woke me up to the complexities of language choices that I made while working with research participants whose first language was not English. What, I continued to ask myself, did I do to the lives of the research participants?

\section{Storied Moment 2: Wondering}

As described above, my first research project was my master's thesis. It began in September 1999 and ended in March 2001. My research focus was to explore the transitional experiences of Chinese international students. The main source of field texts created for this study were transcripts of research conversations in which I engaged with the four participants Jasmine, Magnolia, Mei, and Rose between October 1999 and February 2000. We met as a group every other week on Saturday afternoons, talking about our schooling experiences in both China and Canada. Initially (October and November 1999) the conversations were carried out in English and lasted about an hour. While transcribing the conversations, I realized that there was much more to the participants' experiences than they were able to express in those simple English sentences. I then decided to use Mandarin Chinese for our future conversations, which lasted about two hours. All the conversations were tape-recorded; I listened to the tapes immediately after, and with the English conversations, transcribed them using more grammatically correct forms of English at each participant's request. I translated our Chinese conversations into English sentence by sentence. Each time I completed this process I sent via e-mail to Magnolia, Mei, Rose, and Jasmine copies of the transcriptions and asked each to check them for accuracy. I asked each person to read the 
transcripts, make some comments, or add some thoughts by writing in the margins or on the back of the paper. They did not, however, write anything. They just told me that the English transcripts were "okay." I thought I was doing a good job of faithfully translating their experiences from one language to another. Then, based on these transcripts as well as my research journal, I constructed in English a story or stories about each participant's experiences. Again via e-mail I sent these tentative narrative accounts to Jasmine, Magnolia, Mei, and Rose asking them to confirm the accuracy of my accounts. For the most part, they requested only minor changes and told me that the stories were "okay." I thought I was doing a good job of properly understanding and interpreting their experiences.

As I subsequently looked over these four narrative accounts, I began to see several recurring narrative threads related to their transition experiences. These became the themes that I used to organize and understand their experiences in three contexts: a Chinese high school, a Canadian high school, and a Canadian university. I ended my master's thesis by offering some suggestions and recommendations to both parents and educators in China and educators in Canada in the form of three letters. I wrote everything in English. I thought I was doing a good job of capturing and accurately representing the experiences of Jasmine, Magnolia, Mei, and Rose as international students.

However, my own English poem-writing experience woke me up. I began to wonder about the English and Chinese language choices I was making in my research and how the decisions I made might influence my narrative inquiries and the lives of participants.

\section{Storied Moment 3: Asking Questions about Language Choices}

For the pilot project I mention above, in my doctoral inquiry I met individually with Jasmine, Magnolia, and Mei (Rose did not participate in my doctoral work for personal reasons) for about 90 minutes, asking about their going-home experiences. The conversations were conducted in Mandarin Chinese. Again, I translated them into English sentence by sentence as I transcribed. I then sent these English transcripts to them for their feedback. They requested only minor changes. Again, based on these English transcripts, I wrote in English a tentative narrative account of each participant's experiences and again sent them for responses. Again, neither Magnolia, Mei, nor Jasmine requested any changes.

However, this time I remembered to ask them how they felt when they read the English transcripts and later when they read in English the narrative accounts of their experiences. Magnolia responded by saying, "The conversations in English read more intimate. I don't feel a distance. I don't have a sense of 'Is this what I said?' The narrative account does. I need some time to think about it." If the conversation transcripts in English felt more intimate 
than the narrative accounts, I began to wonder how they would feel if the transcripts were in Chinese.

\section{Storied Moment 4: Doing Things Differently}

Between November 2002 and April 2003, I met one-on-one with Jasmine, Magnolia, and Mei three times for 45-90 minutes. All the research conversations were in Mandarin Chinese and were tape-recorded and later transcribed in Chinese.

This time I did not translate these Chinese transcriptions into English because I did not want my translation/interpretation to interfere with the shape of their stories or responses. Because the topic of home was so close to our hearts and emotions, I believed that it was essential to give Jasmine, Magnolia, and Mei the opportunity to express their innermost feelings and thoughts freely and without effort in their mother tongue.

I then made a photocopy of each transcription and gave them back to Jasmine, Magnolia, and Mei for their feedback. I asked them to feel free to add, delete, change, or comment on the transcription. This time they all responded, and I then made the necessary changes. I read the Chinese transcriptions and their Chinese responses carefully and wrote down some points or questions that I would like to ask about before I met each participant for the next research conversation.

When I asked them how they felt when they read the Chinese transcripts, I was surprised by their answers:

Mei:

I don't know why I feel awkward when I read the Chinese transcript for the first time. I feel more comfortable reading English now.

Magnolia echoed Mei's observation:

It was easy and fast for me to read English. It seemed that I had to slow down and read one character after another when I read Chinese. When Mei and I first saw your Chinese transcript, we laughed. What is this, we asked ourselves, with all those Chinese characters crowded on one page? We hadn't read any Chinese for a very long time. Our eyes were no longer used to reading them any more. At that moment, we felt strange towards the Chinese language. But for me, I still respond to Chinese faster. As soon as I read the transcripts, I can remember the time, the place and the mood of our conversation. As for the English transcripts, it is easier to read. But it took me longer to remember what was happening then. I felt my thoughts were faster as my English got better, but not as fast as when I spoke in Chinese. 
Magnolia also noticed the differing emotional responses that these two languages seemed to evoke in her body:

English conversations seem to read more formal. When I read the conversations in English, I feel as if I was reading another person's story. I don't feel any emotion in it. But when I read the Chinese transcripts, I feel energy, life and passion. I can feel my existence. I can feel I am telling my stories.

In addition to the research conversations, I invited Jasmine, Magnolia, and Mei to do some autobiographical writing. Magnolia and Mei did, but Jasmine did not because she returned to China and did not have time. Although I told them that they could write either in Chinese or in English or both, Magnolia and Mei wrote in English and asked me to "correct all the mistakes" in their writings because they wished to save "all their memories of childhood in China written in English for the first time" onto a disk.

I also invited Jasmine, Magnolia, and Mei to keep a journal during the research process. I gave them each a blank, 72-page, half-plain and half-lined exercise book and asked them to write down any experiences, ideas, feelings, and thoughts that might come to them during the following six months. I also told them that they could write either in English or in Chinese or in both. Jasmine wrote 11 journal entries: only one was in English and the others were all in Chinese. Magnolia wrote six journal entries: only the first was in English and the other five pieces were in Chinese. Mei wrote five journal entries: one in Chinese, one half English and half Chinese, and the other three in English.

After all field texts were collected/created and sorted, I spent many hours reading and rereading them in order to construct interim research textschronicled accounts-about their experiences of home in China and in Canada in English for initial analysis. I used headings Homes in China and Homes in Canada and subheadings First Home, Second Home ... to help me to organize the huge number of field texts into meaningful chunks. I wrote the narrative account of one participant at a time. I finished the three narrative accounts at the end of March 2004. I then shared them with Jasmine, Magnolia, and Mei individually, first in the form of e-mail attachments to ensure that my understandings and representations were respectful and accurate. This sharing usually generated further field texts. Based on their written responses, I revised the accounts and sent them back again for response. In the middle of reading and revising Magnolia's narrative account, I started to look for "the patterns, narrative threads, tensions, and themes" (Clandinin \& Connelly, 2000, p. 132) in her stories. I chose what most stood out for me in each of her stories and gave that story a title. So instead of First Home, Second Home ... Magnolia's stories became My First Home: A Room on a Balcony, My Second Home: I Was an Alarm Clock... I made this new layer of analysis and interpretation with Jasmine's and Mei's stories in the same way. This 
process helped to deepen my understanding of their experiences. I sent these newly revised narrative accounts to Jasmine, Magnolia, and Mei for further response. When they were satisfied with my re-presentation of their individual stories, I sent them each an electronic copy of all the stories I had co-constructed with each of them so that they would have the opportunity to read one another's stories and to respond to them. They each read all the stories with great interest because their experiences of growing up in China had been quite varied. This "member check" (Lincoln \& Guba, 1985, p. 314) technique was crucial for establishing the credibility and validity of my final research text. More important, it allowed me as the researcher to co-construct meaning with my participants based on our shared research experience and to honor and respect their voices.

I struggled for a long time trying to find the right format to re-present Jasmine's, Magnolia's, and Mei's narratives of experiences in my final research text. Finally I decided on a journal format. For example, as soon as I finished one journal entry, Magnolia and I met and we read my writing together. As we sat together working through this process, she gave me her comments and thoughts. I then made the changes that she requested. We did this piece by piece until all six pieces in her chapter were completed. I did the same with Mei's and Jasmine's chapters, and in their chapters included their words in the original Chinese with my English translations.

I felt much better doing my doctoral work in this way although I was often worried about the gaps that might still exist between the constructed stories and their real-life experiences. Magnolia once mentioned this to me:

What you wrote might not be what we wanted to express at that time. This seldom happens. Every time I read my stories in English, it refreshes my memories. I pause and think about it carefully. Is that so? Sometimes I feel very strange. Is that really me? Not really. But when I think really hard about what I told you in our conversations. I think that's me at that time. Now because I have changed, I see the stories differently.

Magnolia's words reminded me again of the importance of working alongside research participants in order to co-construct their life stories in another language.

\section{Ethical Issues in Working with Multiple Languages and Cultures}

\section{Informed Consent}

I still remember my anxiety and hesitation when I was required to obtain a copy of informed consent in written form from each of the research participants in the fall of 1999. I postponed and waited until the last minute for fear 
that this would influence our relationships negatively. Earlier I had already explained to them the purpose of my narrative inquiry and invited them to participate, and all had agreed. We did this orally and in Chinese, which was sufficient and appropriate in the Chinese culture. It did not feel right for me to go back to them and ask for a signed copy in English of their informed consent.

Andrews (2007), who was born and educated in the United States, moved to England for her doctorate in the mid-1980s and has remained there ever since, discussed the tensions that she experienced when she began her life history interviews in East Germany. When she soon realized that "the ideas that are implicit in an informed consent form are entirely inappropriate in the East German context" (p. 496), she decided to abandon the consent forms and "accept the cost that it might have on future publications" (p. 496). Her participants explained that the notion that one can own someone else's words had never been heard of in their culture. They were not concerned about what she might do with the research conversation transcripts and wanted her to use their real names in her representation of their lives. She concluded that "what might be considered ethical in one context may be something very different in another" (p. 496).

As for Andrews' (2007) East German participants, the concept of an informed consent form was foreign to Jasmine, Magnolia, Mei, Rose, and me to understand at that time. In fact, "the very exchange between us on this topic made them somewhat suspicious of me, personally" (Andrews, p. 496). However, I knew that I had to follow the procedural guidelines of the University of Alberta's research ethics review board. With trepidation, I shared my discomfort with them as it might have appeared that I did not trust their spoken words. I was greatly relieved when they understood that "this is the Canadian way of doing things" and signed the forms.

Three years later when I began my doctoral work, I no longer felt as anxious as I had when I asked Jasmine, Magnolia, and Mei for their signatures on the consent form in English. I had learned that it was the beginning of a research process and that in narrative inquiry informed consent is an ongoing process of negotiation between researchers and participants.

\section{Composing Field Texts (Data)}

Clandinin and Connelly (2000) noted that "all field texts are selective reconstructions of field experience and thereby embody an interpretative process" (p. 94). Central to the creation of these field texts is the relationship of researcher to participant:

What is told, as well as the meaning of what is told, is shaped by the relationship. The field texts created may be more or less collaboratively constructed, may be more or less interpretive, and may be more or less researcher influenced. It depends. (pp. 94-95) 
Although I had planned to ask Jasmine, Magnolia, Mei, and Rose to keep journals in English about their first-year experiences in the university as they were living it as another source of field texts for my master's thesis, I finally decided to abandon the plan when I realized how busy their lives were at the time. They were making the transition into a Canadian university, and it was overwhelming for each of them. As they were then eager to practice speaking English, we agreed to conduct our research conversations in English. Besides, I would write my thesis in English. It would save me much time too, or so we thought. When I told them that I would transcribe the tapes verbatim, they asked me to write down what they said in correct English, not their "bad English." However, when I read through the first two transcripts, I realized that those simple English sentences could not possibly contain the complex and sophisticated ideas, thoughts, and feelings that I knew they wished to convey. When we later switched to the Chinese language, our conversations flowed freely and lasted longer. It was more work for me to translate the conversations from Chinese to English, but it was a more authentic and meaningful experience for us all. When I sent the English transcripts and later the English narrative accounts to the participants for feedback, they simply told me that they were "okay." At the time, I thought that I was doing a good job of faithfully translating their experiences from Chinese to English and properly understanding and interpreting their experiences. Now I wonder if that was the case. I wonder who I was in those early days of our relationship. Did Jasmine, Magnolia, Mei, and Rose see me as the "researcher" and feel reluctant to "correct" me in any way? Or did my choice of the English language to capture, analyze, and represent their experiences make it difficult for them to join the research process meaningfully as they were still struggling to learn English?

"What started as a research became a relationship," wrote Lieblich (1996, p. 172). Many of her research participants became friends as did Jasmine, Magnolia, Mei, Rose, and myself. By the time I began my doctoral work, we had known one another for three years. Because of this development in our relationships, we seemed to be more comfortable in telling our life stories, and we even came to anticipate these conversations as spaces for reflection and making sense of our lives together. At the time, I did not realize how profoundly this close relationship would shape the whole inquiry process in varied ways.

When I learned from my pilot project that the English translation of our research conversations might be distancing Jasmine, Magnolia, and Mei from their experiences, I decided to use the Chinese language more in creating field texts for this inquiry. Despite their initial discomfort in reading the Chinese transcripts on a crowded page after being immersed in the English environment for four years, they felt much closer to the Chinese language in capturing and representing who they were as people. Magnolia summarized 
it well by saying, "When I read the Chinese transcripts, I feel energy, life, and passion. I can feel my existence. I can feel I am telling my stories."

In addition to the Chinese transcripts of our research conversations and my field notes and researcher's journal, I also invited Jasmine, Magnolia, and Mei to do some autobiographical writing and keep a research journal. It was interesting to note their language choices: Magnolia and Mei used English to write their autobiographies, and Jasmine did not; for the most part, Jasmine and Magnolia wrote their journal entries in Chinese whereas Mei wrote them in English. As their English-language proficiency increased, they also became increasingly comfortable in expressing their ideas and themselves in the new language. Their language choices seemed to indicate their changing relationships with both the Chinese and English languages and who they were becoming in Canada. In hindsight, I realize that the variety of forms and the nature of the field texts created for this inquiry were more collaboratively constructed, less interpretive, and less researcher-influenced (Clandinin \& Connelly, 2000) than the field texts created for my master's work. As a result, Jasmine, Magnolia, and Mei were more engaged in this part of the inquiry process.

\section{Composing Research Texts}

Josselson (1996) wrote, "Language can never contain a whole person, so every act of writing a person's life is inevitably a violation" (p. 62). She discussed her "intensely anxious and uncomfortable" (p. 63) feeling when she talked with her participants about "how it was for them to find their lives in print-and in words that [she] had written" (p. 63). Although I share her anxiety and discomfort with "writing other people's lives," I wonder if there is a more relational way to address this issue while composing research texts to represent research participants' lives.

Looking back, I believe that as my understanding of the nature of collaborative narrative inquiry deepened, my relationship with my research participants became more collaborative. I believe that my doctoral dissertation was a more co-constructed document than my master's thesis because of the intensity of working alongside Jasmine, Magnolia, and Mei going through layers of analyses and writing multiple drafts of their stories and journal entries. Instead of looking for and creating common themes across participants' stories as I did for my master's thesis, I wrote three chapters of minibiographies in three typefaces, using a journal format, to represent their unique narratives of experiences as individuals over time. I also included their words in Chinese with my English translations so as to honor their voices and experiences and at the same time did not reinforce "the power of English to represent everyone and everything" (Roberts, 1997, p. 170). 
As I conclude this article, I am reminded of Andrews' (2007) words:

Most cross-cultural research is guided by a set of ethical considerations that are irrelevant, unrealistic, and/or possibly inappropriate and insufficient to address the complexity of such encounters. We are better researchers when we push ourselves to confront those aspects of our work that cause us discomfort. (p. 498)

As I move forward to my future inquiries, I know that I need to continue to think in relational ethical ways about what it means to be a narrative inquirer with English-language learners and to remain wakeful (Clandinin \& Connelly, 2000 ) to the language choices I make in capturing, translating, analyzing, and representing narratives of experiences of my future research participants.

\section{The Author}

Yi Li, a former university EFL teacher in China, is currently an assistant professor in the area of second-language education in the Department of Curriculum, Teaching, and Learning, Faculty of Education, University of Manitoba. Her research interests include teaching English as an additional language, teacher education and development, international education, narrative inquiry, and hope.

\section{References}

Andrews, M. (2007). Exploring cross-cultural boundaries. In D.J. Clandinin (Ed.), Handbook of narrative inquiry: Mapping a methodology (pp. 489-511). Thousand Oaks, CA: Sage.

Clandinin, D.J., \& Connelly, F.M. (1988). Studying teachers' knowledge of classrooms: Collaborative research, ethics and the negotiation of narrative. Journal of Educational Thought, 22(2a), 269-282.

Clandinin, D.J., \& Connelly, F.M. (2000). Narrative inquiry: Experience and story in qualitative research. San Francisco, CA: Jossey-Bass.

Connelly, F.M., \& Clandinin, D.J., (2006). Narrative inquiry. In J. Green, G. Camilli, \& P. Elmore (Eds.), Handbook of complementary methods in education research (pp. 477-487). Mahwah, NJ: Erlbaum.

Craig, C.J., \& Huber, J. (2007). Relational reverberations: Shaping and reshaping narrative inquiries in the midst of storied lives and contexts. In D.J. Clandinin (Ed.), Handbook of narrative inquiry: Mapping a methodology (pp. 251-279). Thousand Oaks, CA: Sage.

Josselson, R. (1996). On writing other people's lives. Self-analytic reflections of a narrative researcher. In R. Josselson (Ed.), Ethics and process in the narrative study of lives (vol. 4, pp. 60-71). Thousand Oaks, CA: Sage.

Huber, J., \& Clandinin, D.J. (2002). Ethical dilemmas in relational narrative inquiry with children. Qualitative Inquiry, 8(6), 785-803.

Huber, M., Clandinin, D.J., \& Huber, J. (2006). Relational responsibilities of narrative inquirers. Curriculum and Teaching Dialogue, 8(1/2), 209-223.

Li, Y. (2001). A narrative inquiry of the intercultural and academic transitional experiences of four female Chinese students. Unpublished master's thesis, University of Alberta.

Li, Y. (2006). Where is home: The lived experiences of three Chinese international students in Canada. Unpublished doctoral dissertation, University of Alberta.

Lieblich, A. (1996). Some unforeseen outcomes of conducting narrative research with people of one's own culture. In R. Josselson (Ed.), Ethics and process in the narrative study of lives (vol. 4, pp. 172-184). Thousand Oaks: CA: Sage. 
Lincoln, Y.S., \& Guba, E.G. (1985). Naturalistic inquiry. Beverly Hills, CA: Sage.

Roberts, C. (1997). Transcribing talk: Issues of representation. TESOL Quarterly, 31, 167-172.

Schulz, R. (1997). Issues of care. In R. Schulz (Ed.), Interpreting teacher practice: Two continuing stories (pp. 81-98). New York: Teachers College Press. 